\title{
Los graneros sobreelevados rurales en la Hispania romana: materiales y técnicas constructivas
}

\author{
Rural raised granaries in Roman Spain: \\ materials and construction techniques
}

\author{
Javier Salido Domínguez \\ Universidad Complutense de Madrid \\ pjaviers@hotmail.com
}

\section{RESUMEN}

El presente trabajo pretende ser un acercamiento al análisis de las técnicas empleadas en la construcción de los graneros rurales hispanorromanos dotados de pavimentos sobreelevados. Se presta una especial atención a los materiales constructivos y al empeño que supuso la edificación de estas estructuras rurales específicas que requerían de unos conocimientos precisos para mantener en perfectas condiciones de temperatura y humedad los productos agrícolas en el interior de las cámaras de almacenaje.

Palabras clave: Horrea; graneros; Península Ibérica; técnicas constructivas; materiales constructivos; época romana.

\section{ABSTRACT \\ The present work analyses the building techniques used in the raised granaries from Hispania. It is paid specific attention to the constructive materials and techniques to store grain in good environmental conditions of temperature and humidity.}

Keywords: Horrea; granaries; Hispania; building techniques; constructive materials; roman times.

Recibido: 04-02-2015. Aceptado: 29-09-2015.

Cómo citar este artículo / Citation

Salido Domínguez, J. 2015: "Los graneros sobreelevados rurales en la Hispania romana: materiales y técnicas constructivas", Arqueología de la Arquitectura, 12: e027. doi: http://dx.doi.org/10.3989/arq.arqt.2015.008

\section{Copyright}

(c) 2015 CSIC. Este es un artículo de acceso abierto distribuido bajo los términos de la licencia Creative Commons Attribution-Non Commercial (by-nc) Spain 3.0. 


\section{INTRODUCCIÓN}

Este estudio forma parte de un proyecto de investigación más amplio que iniciamos hace algunos años, cuyo objetivo principal es analizar las técnicas constructivas de la arquitectura rural romana, en concreto, los granaria y horrea destinados al almacenaje de grano y otros productos agrícolas. Además de la lectura de la tesis doctoral $^{1}$, aún inédita, recientemente hemos dado a conocer en trabajos más generales algunas de las cuestiones que nos permiten identificar los graneros rurales romanos, que comprenden los silos de almacenaje de cereal, los granaria sobreelevados y los horrea genéricos (Salido 2003-2004, 2008, 2011b). También recientemente se ha dado a conocer la secuencia crono-estratigráfica y el estudio multidisciplinar del horreum de la villa romana de Veranes (Gijón, Asturias) (Fernández-Ochoa, Gil,Zarzalejos y Salido 2012).

En este trabajo no abordaremos el análisis de los silos y los almacenes genéricos, sino que nos centraremos en el estudio de los graneros sobreelevados, que nos ofrecen la oportunidad de comprender las técnicas específicas aplicadas para la construcción de unas estructuras muy particulares que requerían un especial cuidado en su edificación, al tener una funcionalidad muy precisa: la conservación de productos agrícolas y cereal en el interior de la cámara de almacenaje.

Antes de abordar este trabajo, debemos tener presente las dificultades del análisis, derivadas de la antigüedad de las excavaciones y la ausencia de secuencias estratigráficas, que nos impiden conocer con precisión el momento de construcción de la mayoría de las estructuras de funcionalidad agrícola. Generalmente se han datado a partir del momento de esplendor de la villa, de manera habitual fechadas tras el estudio parcial de los materiales aparecidos en la pars urbana. El análisis reciente publicado sobre el horreum de Veranes, nos debe hacer reflexionar sobre la posibilidad de que ciertas estructuras agrícolas se construyesen en un momento anterior al máximo desarrollo constructivo del establecimiento rural y también sobre la necesidad de reconocer e identificar las distintas reformas que sufrieron los graneros en el momento de su uso que, en el caso del horreum asturiano, supone incluso un cambio de funcionalidad. Por otro lado, debemos tener presente que los análisis más recientes de la arquitectura,

\footnotetext{
Salido Domínguez, J. 2010: Siri, granaria et horrea. Los sistemas de almacenamiento y conservación de grano en el Occidente del Imperio Romano, Tesis doctoral leída en la UAM, Madrid.
}

gracias a la aplicación de la metodología arqueológica, como la estratigrafía de paramentos, han introducido un cambio significativo en el estudio de los edificios, no sólo romanos (Camporeale 2004; Pais 2008; Pizzo 2010a, 2010b), sino también medievales (Caballero 1996; Caballero y Escribano 1996; Fernández y Quirós 2001; Caballero y Utrero 2005). Por desgracia, el arrasamiento de los muros de los graneros hispanorromanos, nos impide conocer con mayor detalle las técnicas que nos informan sobre diferentes etapas constructivas y/o cronológicas de estas construcciones rurales. No obstante, en este estudio presentaremos un acercamiento a las mismas.

\section{PRINCIPIOS CONSTRUCTIVOS DE LOS GRANEROS Y SOLUCIONES TÉCNICAS}

A la hora de referirnos a la construcción de graneros romanos, debemos tener presente que estas estructuras precisan de la aplicación de unos métodos constructivos específicos. Estos edificios se ven notablemente condicionados por las exigencias técnicas relativas a la seguridad estructural de los mismos. La aplicación de unas determinadas técnicas constructivas tienen por objeto evitar los daños que pueden afectar a la cimentación, los soportes, vigas $\mathrm{u}$ otros elementos estructurales, o que reducen su estabilidad. De igual modo, se pretenden aislar de fuentes de posibles incendios, uno de los factores indicados por Vitrubio $(6,6,5)$ respecto al levantamiento de los horrea y granaria2, con el fin de evitar la pérdida de la cosecha.

Además de estos condicionantes, los graneros deben cumplir otros requisitos a la hora de proyectarse, construirse y mantenerse en relación a su funcionalidad. Los graneros sobreelevados constituyen un sistema de almacenaje que tienen la propiedad de conservar el producto en una atmosfera renovada. En estos edificios, el cereal almacenado sigue respirando, obteniendo oxígeno y desprendiendo calor, dióxido de carbono y agua. $\mathrm{Si}$ este proceso continúa durante el tiempo de almacenaje, la fermentación, la aparición de hongos, moho e insectos o la germinación del cereal pueden acabar con la cosecha. Por ello, es necesario frenar este proceso manteniendo el ambiente interno de la cámara de almacenaje en condiciones ideales de temperatura y humedad.

Una de las mayores amenazas para la conservación del cereal son los insectos y ácaros que se crían en el

\footnotetext{
2 Respecto a la distinción de los términos horrea y granaria, véase Salido 2003-2004
} 
interior de los almacenes, tales como: el escarabajo del grano con dientes de sierra (Oryzaephilus surinamensis L.), el gorgojo del grano (Sitophilus granarius, L.), la carcoma achatada del grano (Cryptolestes ferrugineus, Steph.) y el ácaro de la harina (Acarus Siro, L.). La competencia entre estas especies depende de la humedad y de las condiciones de temperatura. Por ejemplo, el gorgojo del grano actúa cuando el ambiente es de $15^{\circ} \mathrm{C}$ y la humedad del 11 $\%$, mientras que el escarabajo del grano con dientes de sierra necesita $20^{\circ} \mathrm{C}$, pero puede soportar condiciones más secas (Gentry 1976: 2-4). En condiciones favorables pueden reproducirse muy rápidamente. Por ello, para almacenar el grano y conservarlo por un periodo de nueve meses a un año en buenas condiciones a granel o en sacos apilados, sin necesidad de ventilarlo, la humedad debe estar en niveles comprendidos entre $10 \%$ y $15 \%$ (ideal es de $14 \%$ ) y la temperatura debe ser de unos $15{ }^{\circ} \mathrm{C}$., condiciones generales que ya conocían los propios agrónomos romanos (Colum. 1, 6, 9-10; 12, 2, 2). La reducción del calor se consigue haciendo pasar el aire a través de las aberturas de ventilación y la parte inferior del suelo (Varro. rust. 1, 57, 1; Plin. nat. 18, 73; Colum. 1, 6, 9-10) o aireando el cereal periódicamente (Vitr. 6, 6, 4), disminuyendo al mismo tiempo el nivel de humedad. Estos factores son los que explican y justifican la construcción de los pavimentos sobreelevados. Para ello, es necesario construir una infraestructura con soportes suficientemente altos para facilitar la entrada del aire por la parte inferior de la cámara de almacenaje y aislar el grano de la humedad del suelo.

La altura de estos apoyos evita además la entrada de animales perjudiciales para la cosecha. Los roedores más frecuentes son la rata (Rattus norvegicus Berk.) y el ratón común (Mus musculus L.). Para evitar su entrada, los hórreos actuales cuentan con una losa de piedra o muela colocada sobre el pegollo, denominada pegoyera o tornarratas, que evita la subida de los roedores desde el suelo (Lozano Apolo y Lozano Martínez-Luengas 2003: 56), sin embargo, no hay constancia de la existencia de estas losas en época romana, porque posiblemente se han considerado una piedra más del granero durante el proceso de excavación.

\section{LOS CONTEXTOS ARQUEOLÓGICOS: LOS GRANEROS SOBREELEVADOS HISPANORROMANOS}

Las investigaciones realizadas en los últimos años nos permiten reconocer los granaria en Hispania (Salido

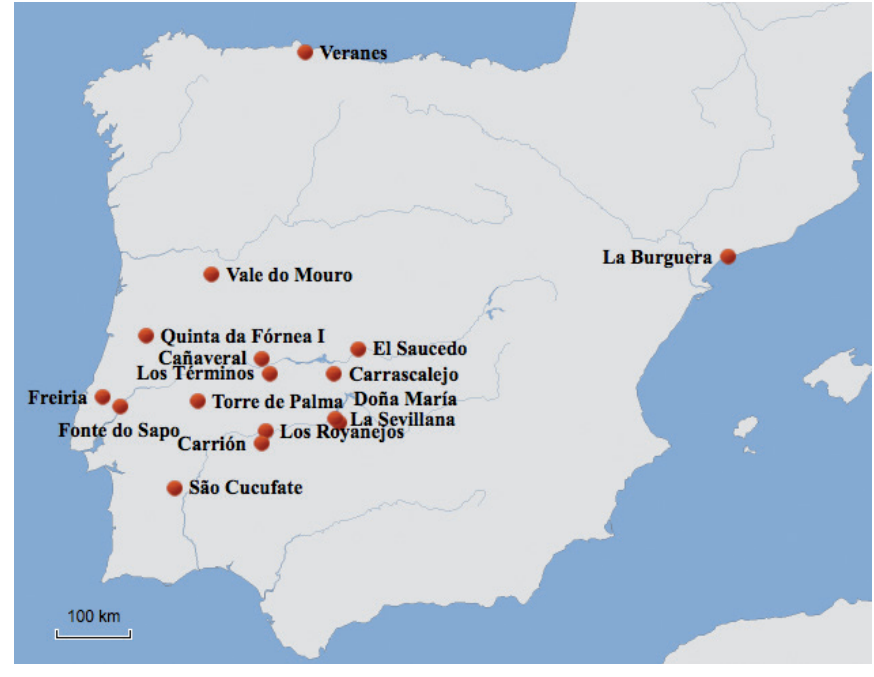

Figura 1. Mapa de distribución de los graneros con pavimento sobreelevado. Imagen: autor.

2003-2004, 2008, 2009, 2011b), una región siempre mencionada como modelo de preservación del grano almacenado mediante el uso de diferentes técnicas de conservación (Varro. rust. 1, 57, 3; Colum. 1, 6, 16) (Fig. 1).

En la Península Ibérica se construyeron graneros sobreelevados en piedra desde por lo menos el siglo VI a. C. (Gracia 1995, 2009; Gracia y Munilla 2000). Los recientes estudios realizados nos permiten determinar que, aunque no supuso una gran novedad en cuanto a la técnica constructiva, sí llegó a convertirse en el modelo de granero más eficaz, pues entre otras muchas ventajas, ofrece la posibilidad de abrir y cerrar la cámara de almacenaje tantas veces como se quiera, de modo que se podía hacer entrega del grano en el momento convenido, sin echar a perder el resto del producto conservado. Es importante tener en cuenta este factor de manera especial, porque muy posiblemente el grano conservado en su interior no sólo se dedicaría como reserva para la cosecha del siguiente año o venta, sino también para el autoabastecimiento de la unidad familiar (Salido 2013: 133).

Datado en el periodo republicano, el horreum de La Burguera (Tarragona) es el más antiguo conocido de época romana, fechado en la segunda mitad del siglo II a. C. (Macías 2011). Este edificio contaba con dos estancias separadas de funcionalidad diferente: una antesala al este que daba acceso a la cámara de almacenaje de mayores dimensiones, dotada de un pavimento apoyado sobre muros paralelos. Este esquema constructivo es el más extendido entre los horrea romanos de los establecimientos rurales altoimperiales (Salido 2003-2004, 2011b), edificios que analizamos en las próximas páginas (Figs. 2 y 3). Sin tratar de repetir los datos ya indicados en trabajos 


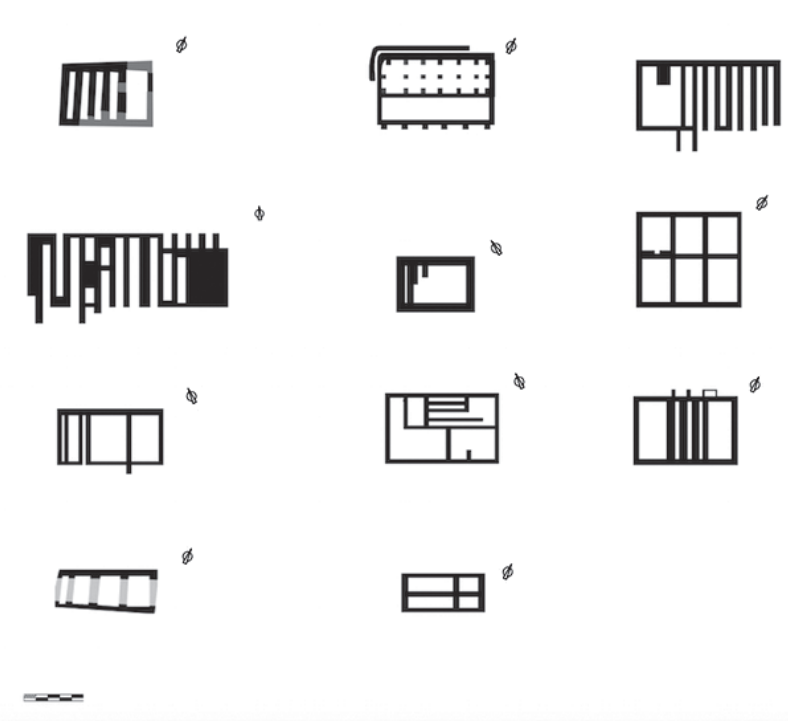

Figura 2. Planta de los graneros con pavimento sobreelevado de la Península Ibérica. En algunos edificios se distinguen dos estancias separadas: una antesala y una cámara de almacenaje apoyada sobre muros o pegollos alineados; a- La Burguera, b- Veranes, c- Los Términos, d- Freiria, e- Carrascalejo, f- São Cucufate (granero de la villa II), g- Carrión, h- Torre de Palma (granero norte), i- Cañaveral, jSão Cucufate (granero de la villa III), k- La Sevillana. Imagen: autor.

anteriores, nos centraremos en aspectos específicos como el estudio de los materiales y las técnicas constructivas, ofreciendo datos concretos, ausentes en trabajos anteriores. Debemos señalar que además en los últimos años hemos podido precisar más la datación de determinados granaria y diferenciar las fases constructivas, como el horreum de la villa romana de Veranes (Asturias), objeto de una monografía reciente (Fernández-Ochoa, Gil, Zarzalejos y Salido 2012) y dar a conocer otros que aún están pendientes de estudio, como el del establecimiento rural de Vale do Mouro (Coriscada, Mêda, Portugal).

\section{LOS MATERIALES CONSTRUCTIVOS}

La importancia secundaria de este tipo de estructuras utilitarias explica el uso masivo de materiales locales, pues no era necesario obtener maderas o piedras foráneas. Son materiales que se podían adquirir en el entorno de los establecimientos rurales. Simplemente se precisaban materiales duros y resistentes para soportar el peso de la techumbre, de los productos conservados y mantener estables los paramentos y pavimentos.

La aplicación de unos criterios de excavación sistemáticos y metódicos permite reconocer en el terreno la construcción de estructuras rústicas edificadas en materiales perecederos como la madera. No cabe duda de que el uso de este material debió ser más frecuente en amplias comarcas forestales y boscosas, pero su escasa documentación en regiones meridionales mediterráneas puede responder más a un problema de índole arqueológico que a una ausencia de tales edificios en época romana. De hecho, el proceso de construcción de la cimentación y del apoyo de las cámaras de almacenaje erigidos en tierra y madera se encuentra bien testimoniado en textos como en la Naturalis Historia de Plinio $(18,73)$. Esta problemática arqueológica se encuentra directamente relacionada con el sistema constructivo en materiales perecederos y sus problemas de conservación. En otros casos, es muy posible que los paramentos y tejados fuesen construidos en madera, mientras que la cimentación se levantó en piedra, lo que nos ofrece más problemas para documentarlas en el registro arqueológico.

La construcción en madera presenta más problemas que el uso de la piedra, porque su origen orgánico hace de éste un material efímero. Los componentes de madera pueden verse involucrados en procesos bióticos (hongos y ciertas familias de coleópteros y de isópteros) o abióticos (a causa de agentes como las variaciones de contenido en humedad, el fuego y las radiaciones ultravioletas). Suele deteriorarse en primer lugar la base del granero, pues los apoyos se hallan en contacto directo con la acción del agua y también el interior donde existen unas condiciones ambientales idóneas para la formación de hongo. Además la estructura se ve amenazada por las larvas de los coleópteros que se alimentan de la madera, la polilla y por el ataque de las carcomas. La madera es un material higroscópico y, por consiguiente, muy sensible a las variaciones de humedad, lo que motiva el hinchamiento que provoca mermas, cambios de volumen que ocasiona fendas, acortamientos y alabeos. Las fendas producidas facilitan la entrada y el desarrollo de los hongos y la colocación de los huevos de los insectos xilófagos. Por último, las radiaciones ultravioleta suponen una degradación de la lignina que posteriormente, al ser eliminada por la lluvia y el viento, hace que las fibras longitudinales pierdan cohesión, la superficie se arrugue, penetre la humedad y en estos huecos, se desarrollan hongos y facilita el depósito de los huevos de los coleópteros (Salido 2011a: 68-69).

A pesar de los problemas de conservación, es posible caracterizar estructuras erigidas en madera y tierra. No cabe duda de que la distribución de evidencias arqueológicas sobre el terreno se encuentra sesgada por la casualidad del hallazgo, pero también es cierto que, a pesar de los numerosos inconvenientes y limitaciones, se 


\begin{tabular}{|c|c|c|c|c|c|c|c|c|}
\hline $\mathbf{N}^{0}$ & Cronología & Provincia & Yacimiento & $\begin{array}{l}\text { Dimensiones/ } \\
\text { superficie }\end{array}$ & Tipología ${ }^{1}$ & Orientación & $\begin{array}{l}\text { Anteslaa o sala } \\
\text { complementaria }\end{array}$ & Bibliografía \\
\hline 1 & $\begin{array}{l}\text { República } \\
\text { (segunda mitad } \\
\text { del siglo II a. C.) } \\
\end{array}$ & Tarraconensis & $\begin{array}{l}\text { La Burguera (Salou, } \\
\text { Tarragona) }\end{array}$ & $7,26 \times 6,55 \mathrm{~m}$ & $\begin{array}{l}\text { Tipo d: } \\
\text { sobre muros } \\
\text { paralelos } \\
\end{array}$ & $\begin{array}{l}\text { Noreste / } \\
\text { sudoeste }\end{array}$ & $\begin{array}{l}\text { sala } \\
\text { complementaria }\end{array}$ & $\begin{array}{l}\text { Macias 2011: 188, } \\
\text { fig. } 1 .\end{array}$ \\
\hline 2 & $\begin{array}{l}\text { Último tercio } \\
\text { del siglo I d.C.)- } \\
\text { segunda mitad } \\
\text { del siglo IV d. C/ } \\
\text { comienzos del V } \\
\text { d. C. } \\
\end{array}$ & Tarraconensis & $\begin{array}{l}\text { Veranes (Gijón, } \\
\text { Asturias) }\end{array}$ & $\begin{array}{l}12,8 \times 8,1 \mathrm{~m} \\
\text { Antesala: } \\
32,40 \mathrm{~m}^{2} \\
\text { Cámara de } \\
\text { almacenaje: } \\
39,44 \mathrm{~m}^{2} \\
\end{array}$ & $\begin{array}{l}\text { Tipo c: } \\
\text { sobre pilares } \\
\text { de piedra }\end{array}$ & $\begin{array}{l}\text { Noreste / } \\
\text { sudoeste }\end{array}$ & Antesala & $\begin{array}{l}\text { Fernández-Ochoa, Gil, } \\
\text { Zarzalejos y Salido } \\
2012 .\end{array}$ \\
\hline 3 & $\begin{array}{l}\text { Altoimperial : } \\
\text { comienzos del } \\
\text { siglo I d.C. }\end{array}$ & Lusitania & $\begin{array}{l}\text { Carrascalejo (Cáceres, } \\
\text { Extremadura) }\end{array}$ & & \begin{tabular}{|l} 
Tipo d: \\
sobre muros \\
paralelos \\
\end{tabular} & $\begin{array}{l}\text { Noroeste / } \\
\text { sudeste }\end{array}$ & $\begin{array}{l}\text { sala } \\
\text { complementaria }\end{array}$ & $\begin{array}{l}\text { Drake 2006: } 216 \text {, figs. } \\
1 \text { y } 5 .\end{array}$ \\
\hline 4 & $\begin{array}{l}\text { Altoimperial : } \\
\text { siglos I-II d.C. }\end{array}$ & Lusitania & $\begin{array}{l}\text { Carrión (Badajoz, } \\
\text { Extremadura) }\end{array}$ & $8 \times 7 \mathrm{~m}$ & $\begin{array}{l}\text { Tipo d: } \\
\text { sobre muros } \\
\text { paralelos }\end{array}$ & $\begin{array}{l}\text { Noroeste / } \\
\text { sudeste }\end{array}$ & $\begin{array}{l}\text { sala } \\
\text { complementaria }\end{array}$ & $\begin{array}{l}\text { Picado 2001: 214, } \\
\text { fig. } 2 .\end{array}$ \\
\hline 5 & $\begin{array}{l}\text { Altoimperial : } \\
\text { primer tercio del } \\
\text { siglo II d.C. }\end{array}$ & Lusitania & $\begin{array}{l}\text { São Cucufate } \\
\text { (Vidigueira, Portugal)- } \\
\text { granero de la villa II }\end{array}$ & $11,5 \times 11 \mathrm{~m}$ & $\begin{array}{l}\text { Tipo f: sobre } \\
\text { diferentes } \\
\text { tipos de } \\
\text { apoyos }\end{array}$ & $\begin{array}{l}\text { Noroeste / } \\
\text { sudeste }\end{array}$ & & $\begin{array}{l}\text { Alarcão, Etienne y } \\
\text { Mayet 1990: 82-83, } \\
\text { fig. L. }\end{array}$ \\
\hline 6 & $\begin{array}{l}\text { Altoimperial : } \\
\text { mediados del } \\
\text { siglo II d.C. }\end{array}$ & Lusitania & $\begin{array}{l}\text { Torre de Palma } \\
\text { (Portalegre, Portugal)- } \\
\text { granero sur }\end{array}$ & & $\begin{array}{l}\text { Tipo d: } \\
\text { sobre muros } \\
\text { paralelos }\end{array}$ & $\begin{array}{l}\text { Noroeste / } \\
\text { sudeste }\end{array}$ & & $\begin{array}{l}\text { Maloney y Hale 1996: } \\
\text { 281, fig. } 4 \text {. }\end{array}$ \\
\hline 7 & $\begin{array}{l}\text { Altoimperial : } \\
\text { mediados del } \\
\text { siglo II d.C. }\end{array}$ & Lusitania & $\begin{array}{l}\text { Torre de Palma } \\
\text { (Portalegre, Portugal)- } \\
\text { granero norte } \\
\end{array}$ & & \begin{tabular}{|l|} 
Tipo d: \\
sobre muros \\
paralelos \\
\end{tabular} & $\begin{array}{l}\text { Noroeste / } \\
\text { sudeste }\end{array}$ & & $\begin{array}{l}\text { Maloney y Hale } 1996 \text { : } \\
\text { 282, fig. } 4 \text {. }\end{array}$ \\
\hline 8 & $\begin{array}{l}\text { Altoimperial : } \\
\text { siglo II d.C. }\end{array}$ & Lusitania & $\begin{array}{l}\text { Freiria (Cascais, } \\
\text { Portugal) }\end{array}$ & $\begin{array}{l}18 \times 7,87 \mathrm{~m} \\
\text { Sala } \\
\text { complementaria: } \\
6,25 \times 4,20 \mathrm{~m}\end{array}$ & $\begin{array}{l}\text { Tipo d: } \\
\text { sobre muros } \\
\text { paralelos }\end{array}$ & Este-Oeste & $\begin{array}{l}\text { sala } \\
\text { complementaria }\end{array}$ & $\begin{array}{l}\text { Encarnação y Cardoso } \\
\text { 1992-1993: fig. } 4 .\end{array}$ \\
\hline 9 & ¿Altoimperial? & Lusitania & $\begin{array}{l}\text { Cañaveral (Cáceres, } \\
\text { Extremadura) }\end{array}$ & $\begin{array}{l}9,50 \text { x } 8,70 \mathrm{~m} \\
\text { Cámara de } \\
\text { almacenaje: } 8,7 \\
\text { x } 6 \text { m } \\
\end{array}$ & $\begin{array}{l}\text { Tipo d: } \\
\text { sobre muros } \\
\text { paralelos }\end{array}$ & $\begin{array}{l}\text { Noreste- } \\
\text { sudoeste }\end{array}$ & Antesala & $\begin{array}{l}\text { Vargas y Matesanz } \\
2006: 117-118 \text {, figs. } \\
1 \text { y } 2 .\end{array}$ \\
\hline 10 & $?$ & Tarraconensis & $\begin{array}{l}\text { Vale do Mouro (Mêda, } \\
\text { Portugal) }\end{array}$ & & & & & Inédito \\
\hline 11 & $?$ & Lusitania & $\begin{array}{l}\text { Fonte do Sapo } \\
\text { (Santarém, Portugal) }\end{array}$ & & & $\begin{array}{l}\begin{array}{l}\text { Noreste / } \\
\text { sudoeste }\end{array} \\
\end{array}$ & & $\begin{array}{l}\text { Moutoso 2006: } 45 \text {, } \\
\text { 219-220, fig. } 15 \text {. }\end{array}$ \\
\hline 12 & ¿Altoimperial? & Lusitania & $\begin{array}{l}\text { Doña María (Badajoz, } \\
\text { Extremadura) }\end{array}$ & & $\begin{array}{l}\text { Tipo d: } \\
\text { sobre muros } \\
\text { paralelos }\end{array}$ & & & $\begin{array}{l}\text { Aguilar y Guichard } \\
\text { 1993: 110-111, fig. } 34 .\end{array}$ \\
\hline 13 & ¿Altoimperial? & Lusitania & $\begin{array}{l}\text { Los Royanejos } \\
\text { (Mérida, Extremadura) }\end{array}$ & $10,25 \mathrm{~m}^{2}$ & $\begin{array}{l}\text { Tipo d: } \\
\text { sobre muros } \\
\text { paralelos }\end{array}$ & $\begin{array}{l}\text { Noreste / } \\
\text { sudoeste }\end{array}$ & & $\begin{array}{l}\text { Olmedo y Vargas } \\
\text { 2004: 37, fig. } 23 .\end{array}$ \\
\hline 14 & ¿Altoimperial? & Lusitania & $\begin{array}{l}\text { Los Términos/ Monroy } \\
\text { (Cáceres, Extremadura) }\end{array}$ & $\begin{array}{l}14 \times 7,15 \mathrm{~m} \\
\text { Sala } \\
\text { complementaria: } \\
4-4,50 \times 7, \\
15 \mathrm{~m} \\
\text { Cámara de } \\
\text { almacenaje: } \\
10 \times 7,15 \mathrm{~m} \\
\end{array}$ & $\begin{array}{l}\text { Tipo d: } \\
\text { sobre muros } \\
\text { paralelos }\end{array}$ & $\begin{array}{l}\text { Noreste / } \\
\text { sudoeste }\end{array}$ & $\begin{array}{l}\text { sala } \\
\text { complementaria }\end{array}$ & Cerrillo 2006: fig. 10. \\
\hline 15 & ¿Altoimperial? & Lusitania & $\begin{array}{l}\text { Quinta da Fórnea I } \\
\text { (Belmonte, Portugal) }\end{array}$ & $21 \times 11 \mathrm{~m}$ & $\begin{array}{l}\text { Tipo c: } \\
\text { sobre pilares } \\
\text { de piedra }\end{array}$ & $\begin{array}{l}\text { Noreste / } \\
\text { sudoeste }\end{array}$ & & Santos 2009: 26 y 50. \\
\hline 15 & Bajoimperial & Lusitania & $\begin{array}{l}\text { São Cucufate } \\
\text { (Vidigueira, Portugal)- } \\
\text { grenier de la villa III }\end{array}$ & & $\begin{array}{l}\text { Tipo d: } \\
\text { sobre muros } \\
\text { paralelos }\end{array}$ & $\begin{array}{l}\text { Noreste / } \\
\text { sudoeste }\end{array}$ & $\begin{array}{l}\text { sala } \\
\text { complementaria }\end{array}$ & $\begin{array}{l}\text { Alarcão, Etienne y } \\
\text { Mayet 1990: } 136 .\end{array}$ \\
\hline 16 & $\begin{array}{l}\text { Bajoimperial: } \\
\text { finales del siglo } \\
\text { IV }\end{array}$ & Lusitania & $\begin{array}{l}\text { La Sevillana (Badajoz, } \\
\text { Extremadura) }\end{array}$ & & $\begin{array}{l}\text { Tipo d: } \\
\text { sobre muros } \\
\text { paralelos } \\
\end{array}$ & $\begin{array}{l}\text { Noreste / } \\
\text { sudoeste }\end{array}$ & & $\begin{array}{l}\text { Aguilar y Guichard } \\
\text { 1993: 123, fig. } 43 \text {. }\end{array}$ \\
\hline 17 & Bajoimperial & Lusitania & $\begin{array}{l}\text { El Saucedo (Toledo, } \\
\text { Castilla-La Mancha) }\end{array}$ & & $\begin{array}{l}\text { Tipo f: sobre } \\
\text { diferentes } \\
\text { tipos de } \\
\text { apoyos }\end{array}$ & $\begin{array}{l}\text { Noreste / } \\
\text { sudoeste }\end{array}$ & $\begin{array}{l}\text { sala } \\
\text { complementaria }\end{array}$ & $\begin{array}{l}\text { Castelo, López Sáez, } \\
\text { López Pérez, Peña, } \\
\text { Liesau, Ruiz, López } \\
\text { Merino, Pérez, García, } \\
\text { Gómez, y Manglano } \\
\text { 2010-2011. }\end{array}$ \\
\hline
\end{tabular}

${ }^{1}$ Según la tipología propuesta por Salido 2010.

Figura 3. Características y tipología de los graneros rurales hispanorromanos. Imagen: autor. 
han producido innegables avances en este campo, y por primera vez contamos con herramientas técnicas y metodológicas para definir un nuevo paradigma o protocolo de actuación científica en la investigación de los establecimientos rurales romanos, con especial atención a las estructuras dedicadas a la transformación y almacenaje de productos agrícolas. Las excavaciones arqueológicas deben propugnar la identificación de estas construcciones de madera a partir de los restos de estructuras constructivas negativas, practicadas por debajo del nivel natural del terreno, a modo de agujeros, trincheras o zanjas de cimentación, que estuvieron destinadas a albergar los durmientes en madera para fundamentar construcciones sustentadas mediante postes, cuyas huellas han quedado marcadas sobre el terreno. Otra prueba de su existencia es el hallazgo y documentación de la madera carbonizada correspondiente a la cámara de almacenaje e incluso del grano que fue almacenado en el momento de su abandono o destrucción. Dentro de las nuevas líneas de trabajo, se hace necesario también documentar la presencia de clavos y material de construcción conservados en hierro, que pueden identificarse a partir del uso de detectores de metales bajo supervisión científica, que pueden aportar pruebas concluyentes sobre la existencia de graneros de madera. También la recogida de muestras y el análisis paleobotánico de las muestras recogidas permiten confirmar la funcionalidad de determinadas estructuras de madera, así como el estado del cereal (en estado de germinación, carbonizado, etc.), que nos aporta muchos datos sobre el sistema de almacenaje y abandono del edificio (Salido 2008: 696-697). Los estudios más recientes plantean incluso la necesidad de tener presente la construcción de graneros de madera construidos sobre postes inclinados que nos informan de la existencia de techumbres inclinadas y de la posible prueba de la existencia de contrafuertes o refuerzos en este tipo de edificaciones (Blaising y Vanmoerkerke 2005: 37).

En el caso hispano, son todavía escasos los estudios antracológicos aplicados al estudio de los graneros rurales. Recientemente se ha dado a conocer el análisis de las maderas documentadas en el horreum de El Saucedo donde se ha podido registrar el uso de $P$. pinaster (pino resinero) para la construcción del tabulatum (Castelo, López Sáez, López Pérez, Peña, Liesau, Ruiz, López Merino, Pérez, García, Gómez, y Manglano 2010-2011), un material que debió emplearse de forma recurrente por sus buenas propiedades para la construcción, mucho más ligero que otras maderas duras, lo que explica su documentación en otros yacimientos romanos (Domer- gue y Hérail 1978). Aunque es cierto que no tiene una vida tan larga y produce mayor cantidad de astillas, el uso práctico, para la construcción de la tarima, justifica su utilización. En el entorno de la villa romana de Veranes (Asturias), incluso se ha podido documentar que en la segunda mitad del siglo IV d. C. se reforestó con diversas especies de pinos, tanto resineros (Pinus pinaster) como posiblemente piñoneros (Pinus halepensispinea tipo) (López 2012: 168). La extensión del pino, así como del castaño, también ha sido confirmada en el análisis polínico del yacimiento romano de Paredes (Jiménez, González, Requejo y Ruiz 2004) entre los siglos III-VI d. C., donde puede afirmarse el cultivo del segundo en un ambiente muy antropizado. A diferencia de otras regiones donde la madera del tabulatum se importó desde regiones lejanas, como se ha podido comprobar en el granero militar de Thamusida, construido con castaño que no es originario de Marruecos (Papi y Martorella 2007), en Hispania a tenor de los datos conocidos parece que se optó por materiales locales.

Además de la madera, se emplearon muy posiblemente otros materiales poco reconocibles en el registro arqueológico, también combinados con ésta, que permitieron levantar estructuras rústicas de manera eficiente y rápida. Es el caso del uso del adobe, el tapial o el sistema de crates, es decir, paja, caña o ramas unidas mediante cordaje para el levantamiento del maderamen interno de la estructura. Para su uso concreto en la construcción de horrea, predominantemente en regiones secas, requiere de su aislamiento con respecto al suelo mediante la instalación de un zócalo de piedra, a menudo aparejado en seco, para evitar que absorba la humedad del terreno, sobre todo cuando llueve. Este tipo de material presenta además ciertas ventajas frente al uso de otros materiales como la piedra (Bacchetta 2003: 122). Entre estas, podemos destacar la accesibilidad y sencilla obtención del mismo, sin complejos procesos de extracción, de modo que resulta menos costoso desde el punto de vista económico, la ventajosa proporción peso/resistencia, muy funcional para la construcción de alzados de gran altura o de estructuras de difícil estabilidad constructiva como los graneros suspendidos en altillos, etc., documentados en algunas residencias de Herculano (Monteix 2008), permite conseguir un buen aislamiento térmico y es flexible en cuanto a su uso, pudiéndose adaptar a las transformaciones funcionales del edificio.

Las magníficas características de la piedra para su empleo en obra, principalmente por su gran resistencia mecánica a compresión y su resistencia a los agentes at- 
mosféricos, hacen de este material uno de los elementos más utilizados en la construcción de los graneros rurales. El material puede ser variado, siendo empleado más frecuentemente el guijarro o canto rodado que la piedra obtenida directamente en las canteras, sobre todo en técnicas mixtas de construcción lapídeo-latericias. Esto se debe en la mayoría de los casos a la ubicación de los establecimientos rurales en zonas próximas a los cursos fluviales y en contextos de llanura alta de donde, traídos por las corrientes de agua o los corrimientos de tierra, son obtenidos directamente. A nivel general, la disposición de los elementos pétreos mantiene una cierta modalidad homogénea y coherente, con un paramento externo formado por piedras de mayor tamaño que los del núcleo interno, técnica que responde a una cuestión práctico-funcional. No obstante, debemos destacar que, en la mayoría de los casos, conocemos solamente la cimentación de los edificios, de modo que no sabemos si el alzado se construiría en madera. También era frecuente el empleo de materiales de unión como la arcilla o el mortero de cal, siempre condicionado por su disponibilidad. Se utiliza masivamente la piedra local para la construcción de los graneros, como la pizarra o el cuarzo blanco en el horreum de Monroy (Salido 2003-2004: fig. 2) (Figs. 4 y 5) o el granito en el horreum de El Saucedo (Castelo, López Sáez, López Pérez, Peña, Liesau, Ruiz, López Merino, Pérez, García, Gómez y Manglano 2010-2011: 216). Los muros del granero de Veranes están construidos con lajas de piedra caliza de tendencia paralepípeda, colocadas con la cara trabajada hacia el exterior y utilizando pequeñas piedras como cuñas y relleno en el interior de las paredes (Fernández-Ochoa, Gil, Zarzalejos y Salido 2012: 131) (Fig. 6). El mortero aglutinante tiene color blanquecino y es muy consistente. Los paramentos del horreum no presentan en su composición fragmentos de latericio o piedras areniscas, aspecto importante, ya que la mayoría de los muros bajoimperiales de la villa, además de contener un mortero amarillento, menos consistente y de granulometría más fina, muestran en sus rellenos fragmentos de tejas, ladrillos y areniscas reutilizados.

\section{LAS TÉCNICAS DE CONSTRUCCIÓN}

\subsection{Los paramentos}

Los granaria de piedra se cimentan sobre una base muy sólida, resistente y equilibrada que ofrece estabilidad y consistencia a la superestructura. La anchura media de los
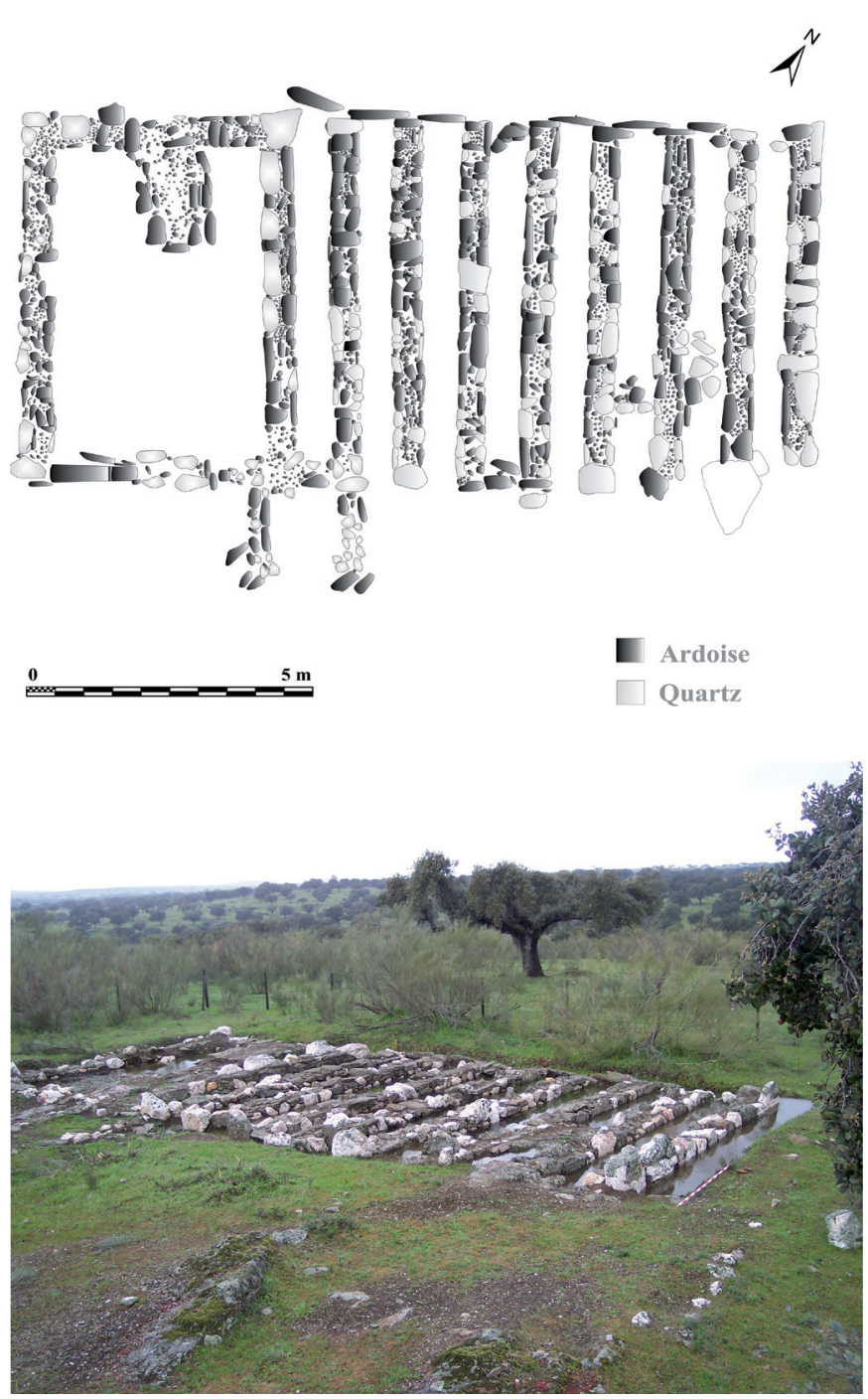

Figura 4. Vista general y planta del horreum de la villa romana de Monroy (Extremadura). Imagen y fotografía: autor.

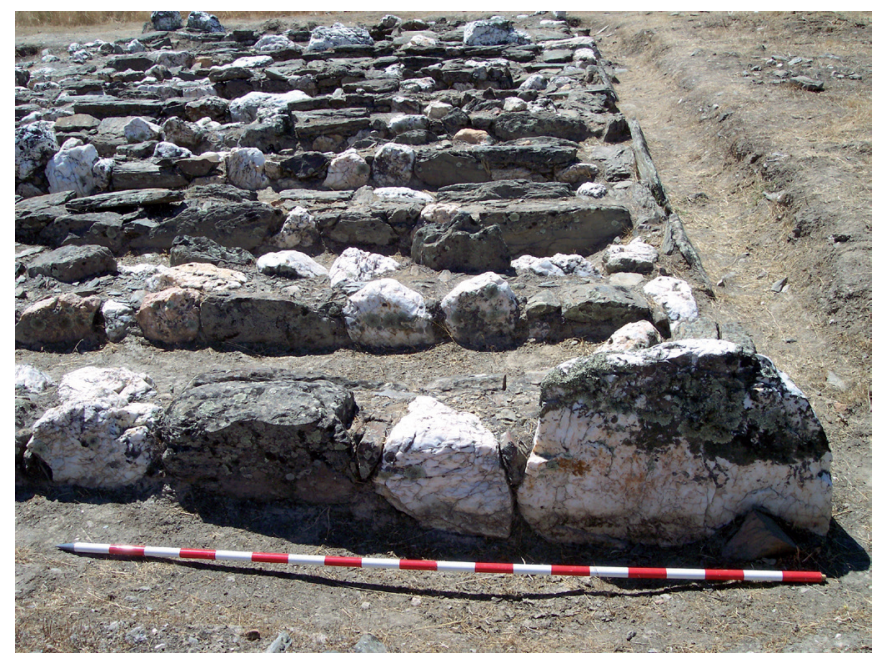

Figura 5. Detalle del aparejo de los muros fabricados con cuarzo y cantos rodados del horreum de la villa romana de Monroy (Extremadura). Fotografía: autor. 

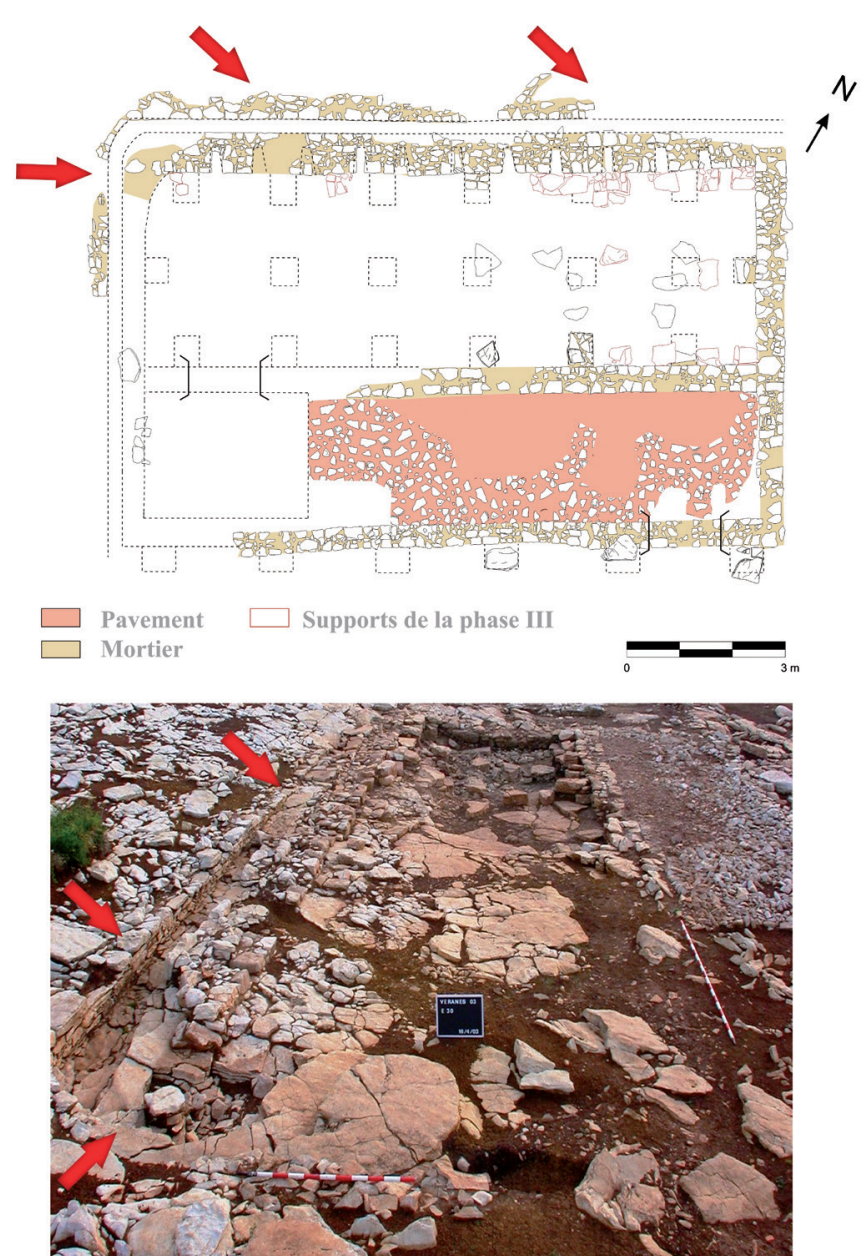

Figura 6. Vista general del horreum de Veranes (Asturias) durante los trabajos de excavación de 2003 y planta del edificio, con indicación del canal del drenaje. Imagen: Fernández Ochoa et alii 2013, figs. 53 y 58.

muros perimetrales no es inferior a los dos pies romanos $(0,6 \mathrm{~m})$; por el momento desconocemos la profundidad de las zanjas de cimentación de los paramentos exteriores para los granaria hispanorromanos -en otras regiones alcanzan hasta $1 \mathrm{~m}$ (Salido 2011a: 69)—. Estos paramentos contaban en ocasiones con aberturas de ventilación que solían encontrarse en el nivel inferior del pavimento para facilitar la entrada de corriente de aire $y$, de este modo, favorecer la ventilación de la cámara de almacenaje ${ }^{3}$. Es de notar que en algunos graneros como Veranes (Asturias), estas aberturas presentaban un cierto abocinamiento, es decir, un ensanchamiento del vano hacia el lado interno de la pared en forma de cuña que facilitaba la circulación del aire por la parte inferior de la cámara de almacenaje (FernándezOchoa, Gil, Zarzalejos y Salido 2012: 133) (Fig. 7).

3 Al igual que el horreum de Veranes, algunos muros han conservado las aberturas de ventilación, como el granero de Niederzier, Hambach 111 (Heimberg 2002-2003) y el de Panossas «Les Buissières» (Rhône-Alpes) (Poux, Borlenghi, Courtot, Leperlier, Blanc y Lassus 2012: 70-140).

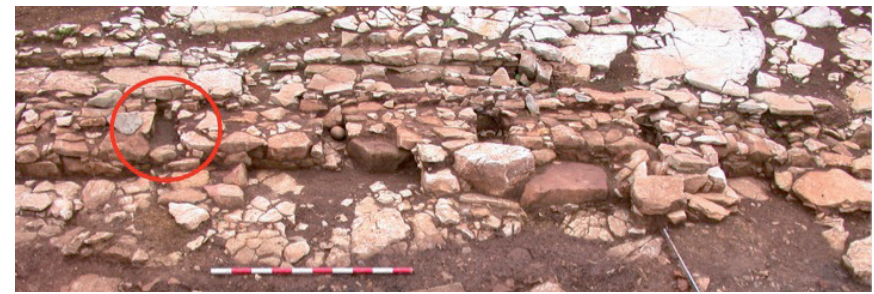

Figura 7. Aberturas de ventilación del muro norte del granero de Veranes (Asturias) con indicación de una que presenta un mayor abocinamiento. Imagen: Fernández Ochoa y Gil Sendino.

A menudo se excavaron canales de drenaje que evitaban encharcamientos en las inmediaciones de las zanjas de cimentación de los muros, bien reconocidos en horrea militares (Salido 2011a: 109) y en algún granero rural como en Veranes (Fernández-Ochoa, Gil, Zarzalejos y Salido 2012: 49). En el almacén de Monroy (Extremadura), se colocaron varias lajas de piedra en el extremo norte con el fin de cerrar los vanos situados en la parte inferior del entarimado de madera y, de este modo, conseguir que el aire pasara al interior del edificio por el lado sureste, ventilara el grano almacenado, mientras se aislaba de la humedad este extremo del edificio (Salido 2003-2004: 472) (Fig. 8).

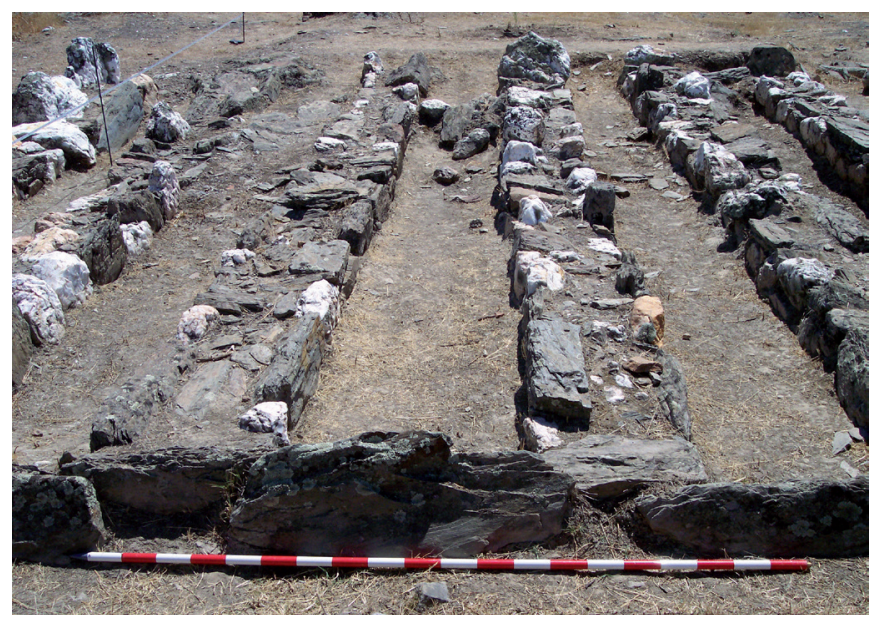

Figura 8. Cierre del extremo oriental del granero de Monroy (Extremadura) con lajas de piedra. Imagen: autor.

En cuanto a los alzados, por el momento no se han documentado vanos en las fachadas ${ }^{4}$, aunque tanto la etnografía como los textos clásicos (Varrón, rust. 1, 57; Plin. nat. 18, 73) nos informan sobre su existencia. La apertura de estas ranuras, junto al peso ejercido por la techumbre, obligó a la construcción de contrafuertes que reforzaban los paramentos, como los documentados en

\footnotetext{
${ }^{4}$ Las únicas ventanas localizadas corresponden a almacenes polivalentes como el de la villa romana de Meonstoke (King 1996) o el horreum urbano de Tréveris (Eiden y Mylius 1949).
} 
Freiria (Portugal) o Cañaveral (Extremadura). Los contrafuertes además de contrarrestar el peso de la techumbre y reforzar los paramentos que disponen de aberturas de ventilación e incluso de ventanas, servía para aguantar la presión ejercida por el cereal almacenado en caso de que este se almacenase a granel pues, en ese caso, actúa como un semifluido y su peso ejerce una enorme presión hacia los laterales. Especialistas como Gentry (1976: 18) defienden que el almacenaje de cereal a granel es un método poco práctico, porque de este modo no se podría separar el grano recientemente almacenado del antiguo y se impide también el aventamiento del cereal; por ello, plantea que posiblemente se almacenara en sacos. Sin embargo, estudios arqueobotánicos recientes concluyen que el almacenaje a granel (en forma de espigas o grano) era común en algunos horrea romanos (Matterne, Yvinec, Gemehl y Riquier 1998; Matterne 2001).

La ausencia de muros perimetrales en determinados horrea, como el de la villa romana de Monroy (Extremadura) nos llevan a pensar incluso en la construcción de cámaras de almacenaje de madera apoyadas sobre una cimentación de piedra. Todavía aún es frecuente la construcción de este tipo de hórreos como el tipo asturiano.

\subsection{Los pavimentos sobreelevados}

Los pavimentos eran generalmente construidos en madera mediante tablones y vigas ensamblados que se apoyaban directamente sobre los soportes inferiores. Los agrónomos romanos se refieren a estos suelos como sobrados de madera o entarimados, bajo el concepto latino de tabulatum/a (Varro. rust. 1, 13, 1; 3, 2, 6; Colum. 1, 6, 9-10). Este entarimado es la base sobre la que se almacena el cereal. En el registro arqueológico, son perceptibles a partir de restos arqueológicos indirectos, tales como la presencia de mechinales en los que se insertaban las vigas de madera, el hallazgo de numerosos clavos pertenecientes al sobrado, la amplia separación de los soportes - lo que indica que los pavimentos debían estar construidos con vigas y tablones de mayor longitud - o la aparición de sedimentos que contienen restos carbonizados de la madera del sobrado (Salido 2011a: 108).

El estudio particular del horreum de Veranes (Asturias) publicado permite comprender cómo se disponían las vigas de madera para mantener perfectamente estable el tabulatum (Fernández-Ochoa, Gil, Zarzalejos y Salido 2012: 178). Parece evidente que los apoyos internos de la cámara de almacenaje servían de soporte de planchas de madera y vigas de madera horizontales sobre los que iba encajado un pavimento formado por tablones (Fig. 9). La estabilidad que concedían estos soportes era suficiente para aguantar un peso considerable de grano. Así pues, se crea un sistema de ventilación en la parte inferior del pavimento que permite la entrada de corriente de aire procedente del oeste y del este por el interior de los arcos. Por otro lado, los abundantes clavos aparecidos durante la excavación nos han permitido determinar, por su tamaño y contexto cronológico, corresponden a la tarima de

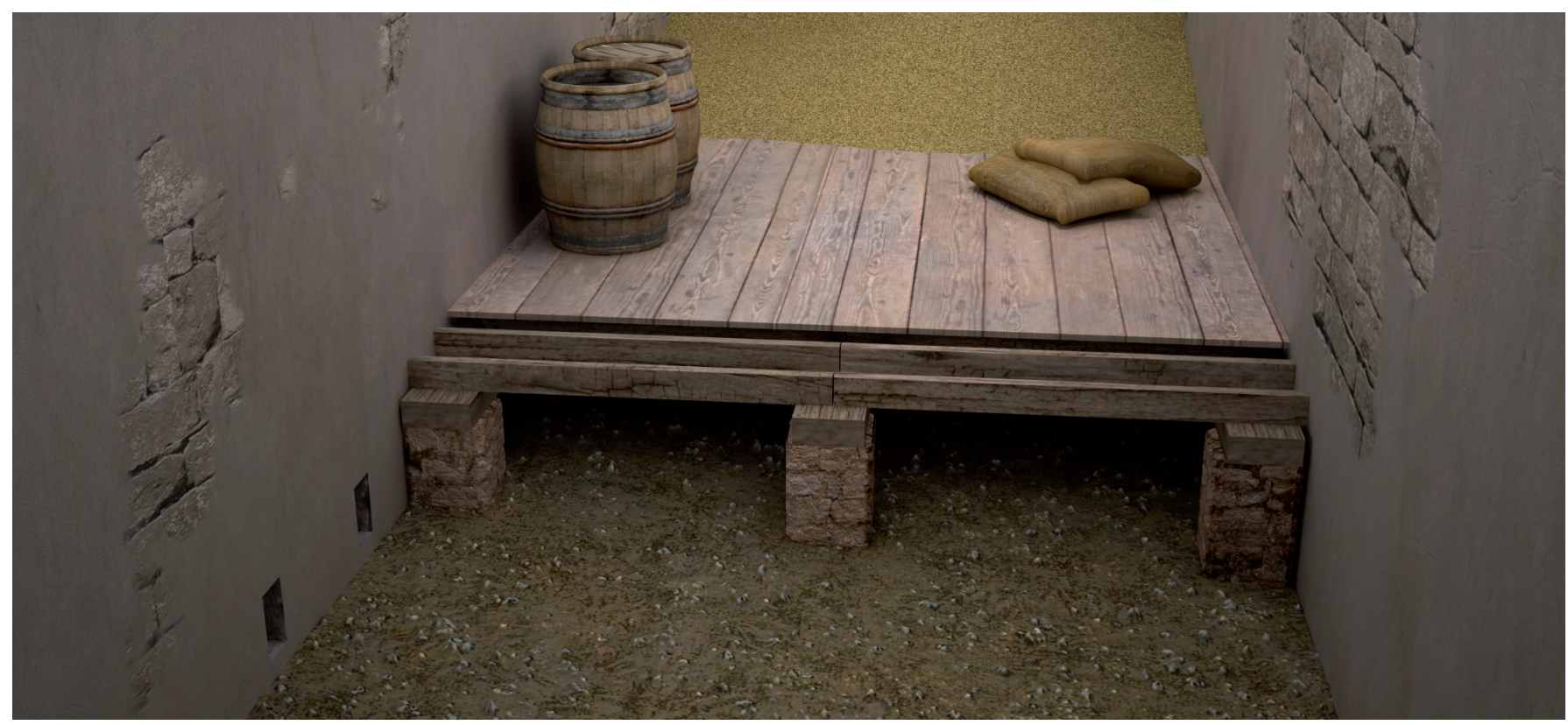

Figura 9. Reconstrucción del interior de la cámara de almacenaje del horreum de Veranes (Asturias). Imagen: Fernández-Ochoa, Gil, Zarzalejos y Salido 2012: Figura57. 
madera del granero y testimonian la reparación o sustitución del mismo en dos ocasiones, coincidentes con las fases del edificio (Fernández-Ochoa, Gil, Zarzalejos y Salido 2012: 68-69). También como hemos indicado anteriormente, en la villa romana de El Saucedo (Toledo) se han podido realizar análisis antracológicos que confirman que los carbones pertenecientes a la tarima del granero, de la que aún se conserva una viga quemada, corresponde a Pinus pinaster (pino resinero) (Castelo, López Sáez, López Pérez, Peña, Liesau, Ruiz, López Merino, Pérez, García, Gómez y Manglano 2010-2011: 214). Los pavimentos de las cámaras de almacenaje no sólo se construyeron en madera (tabulata), sino también en otros materiales como la pizarra, como por ejemplo, en La Sevillana. En cambio, no se conocen pavimentos en opus signinum, hasta el momento solamente identificados en horrea militares y fechados a partir del siglo II d. C. (Salido 2011a: 108).

\subsection{Los soportes de los pavimentos sobreelevados}

Los pavimentos de las cámaras de almacenaje se apoyaban sobre distintos soportes: pegollos o pilares de piedra, muretes paralelos o varios tipos de apoyos que nos han permitido establecer una clasificación técnico-tipológica de los horrea romanos militares (Salido 2011a: 71) que aplicamos en este trabajo a los graneros rurales hispanorromanos. Esta clasificación se realiza siguiendo las tipologías de graneros ya publicadas en trabajos anteriores, ya sean urbanos o portuarios (Rickman 1971: 77 y 227-228; Papi y Martorella 2007; Virlouvet 2009), rurales (Demarez 1987; Sigaut 1988: 6; Morris 1979; Van Ossel 1992) o militares (Manning 1975; Gentry 1976). Estas clasificaciones se han propuesto a partir de la existencia o ausencia de los apoyos de la cámara sobreelevada, puesto que constituyen un argumento definitorio para plantear su uso como almacén de alimentos perecederos como el cereal.

\subsubsection{Graneros apoyados sobre pilares de piedra}

El empleo de pilares precisó un estudio concreto de la inclinación de los pavimentos o tabulata para mantenerlo horizontal y perfectamente equilibrado, lo que hace de éste un apoyo poco práctico. Este tipo constructivo se constata en ámbito rural a partir de la segunda mitad del siglo I d. C., coincidiendo con la época flavia, un fenómeno que ya identificamos en el estudio de los horrea militares (Salido 2011a: 86). En Hispania, por el momento solamente se han localizado dos graneros de este tipo. Es el caso del horreum de la villa romana de Quinta da Fórnea I (Belmonte, Portugal) (Santos 2009: 26 y 50) y de Veranes (Asturias, España) (Fernández-Ochoa, Gil, Zarzalejos y Salido 2012).

Respecto a la problemática arqueológica, tenemos que tener presente la importancia de estos soportes, pues en ocasiones se han retirado o desplazado sin constatar su presencia en los planos de trabajo. En otras ocasiones, debieron ser reutilizados para la construcción de nuevas estructuras, de modo que su ausencia en la excavación nos impide confirmar la función de un almacén como granero. De igual modo, algunas pilastras pudieron servir como apoyos del suelo y no de la techumbre 5 . La localización de soportes in situ nos ofrece información determinante para conocer la posición de éstos, ya que generalmente se disponen a una distancia de separación equidistante y se suelen colocar entre las aberturas de ventilación de la fachada para no bloquear el conducto de aire. También el registro de pilares in situ nos permite saber la profundidad aproximada en la que estaban hincados en el terreno y, de este modo, podemos conocer la altura a la que estaba situado el pavimento con respecto al nivel de suelo. Los cambios en la disposición de los apoyos nos informan además sobre reformas importantes en el edificio. Así por ejemplo en el granero de Veranes (Gijón, España), pudimos identificar en la fase III (fines del siglo III d. C.-comienzos del IV d. C.) una nueva disposición de los soportes que implicó la anulación de los orificios de aireación de la construcción original, lo que supuso un importante cambio en la funcionalidad del edificio que pasó a ser un almacén con una función polivalente (Fernández-Ochoa, Gil, Zarzalejos y Salido 2012: 48).

\subsubsection{Graneros apoyados sobre muretes de piedra}

Desde el punto de vista constructivo, la disposición de muretes internos paralelos presenta una mayor facilidad que otros soportes, porque responde a los mismos criterios y principios que los empleados en la cimentación de los paramentos externos del granero. De igual modo, ofrece notables ventajas, pues permite colocar fácilmente el pavimento de un modo equilibrado y constituye el mejor soporte para almacenar una carga pesada, al contar con gran superficie de sujeción.

\footnotetext{
${ }^{5}$ Es el caso de los horrea de Hauts de Clauwiers (Nord-Pas-de-Calais, Francia) (Révillion, Bouche y Wozny 1994), el almacén de Biberist-Spitalhof (Solothurn, Suiza) (Schucany 2006); en otros casos, la enorme distancia de separación de los apoyos nos lleva a dudar sobre su uso como soporte de un pavimento, como en la villa romana de Cal.lípolis (Cataluña) (Salido 2013: 136 , nota 12$)$.
} 
En el terreno no siempre resultan fáciles de identificar estos apoyos debido al arrasamiento de los muros o por la constatación de uno solo en el interior de la estancia encontrada. En ocasiones, se hace mención también a estos muretes como soportes del pavimento, aunque la distancia de separación nos impide interpretarlos como tal. También es conveniente tener presente que no siempre un edificio o estancia con muros internos debió cumplir la función de granero, pues en terrenos especialmente anegados, estos sistemas de sobreelevación pudieron servir como un simple método de aislamiento (Royet, Berger, Bernigaud y Royet 2004: 269).

A pesar de los diferentes problemas de índole arqueológica indicados anteriormente, podemos afirmar que en la actualidad constituyen el tipo de apoyo mejor documentado y el más común en los graneros del Mediterráneo occidental. Probablemente la piedra utilizada en la construcción de los muretes internos no es tan aprovechable como los pegollos o pilares y nos resulta más fácil de identificar los muros paralelos que simples piedras trabajadas utilizadas como soportes del pavimento. Este tipo de construcción tan estable permite construir horrea de grandes dimensiones, como el horreum de Freiria (Cascais, Portugal) que mide $12 \mathrm{~m}$ de longitud y $8 \mathrm{~m}$ de anchura (fig. 10), de momento el de mayores dimensiones de los documentados en Hispania.

Se constata este apoyo en gran parte de los establecimientos rurales del occidente del Imperio de época altoimperial. Se generaliza su uso en el siglo II d. C., aunque todavía en época bajoimperial es el soporte más empleado en la construcción de los horrea romanos. En la Península Ibérica, se han podido documentar estas cámaras de almacenaje en edificios aislados. Es el caso de los granaria de La Burguera (Tarragona) (fig. 2a; fig. 3, n ${ }^{\circ}$ ), Los Términos/Monroy (Cáceres, Extremadura) (fig. 2c; fig. 3, no 14), Carrascalejo (Cáceres, Extremadura) (fig. 2e ; fig. 3, nº 3), São Cucufate (Beja, Portugal) — graneros de la villa II y III- (fig. 2 f y j; fig. 3 , no 5 y 15), Freiria (Cascais, Portugal) (fig. 2d; fig. 3, $\mathrm{n}^{\mathrm{o}}$ 8), Vale do Mouro (Coriscada, Mêda, Portugal) (fig. 3, n 10), Fonte do Sapo (Santarém, Portugal) (fig. 3, n ${ }^{\circ} 11$ ), Doña María en Esparragosa de Lares (Badajoz, Extremadura) (fig. 3, $\mathrm{n}^{\circ}$ 12) y Los Royanejos en Mérida (Badajoz, Extremadura) (fig. 3, no 13).

En otros establecimientos rurales, los graneros son estancias que forman parte de ciertas construcciones polifuncionales, como los almacenes de cereal de Cañaveral (Cáceres, Extremadura) (fig. 2i; fig. 3, no 9), Carrión (Badajoz, Extremadura) (fig. 2g; fig. 3, $n^{\circ} 4$ ), La Sevillana en Esparragosa de Lares (Badajoz, Extremadura) (fig. 2k; fig. $3, n^{\circ} 16$ ) y los denominados graneros norte y sur de la villa romana de Torre de Palma (Portalegre, Portugal) ( $c f$. Salido 2011b: 134-135; 2013: 133-135) (fig. 2h; fig. 3, no 6 y 7).

\subsubsection{Graneros apoyados sobre varios tipos de soportes}

La colocación de diferentes soportes permite disponer el tabulatum perfectamente equilibrado en un plano completamente horizontal $\mathrm{y}$, bien sujeto, consiguiendo una

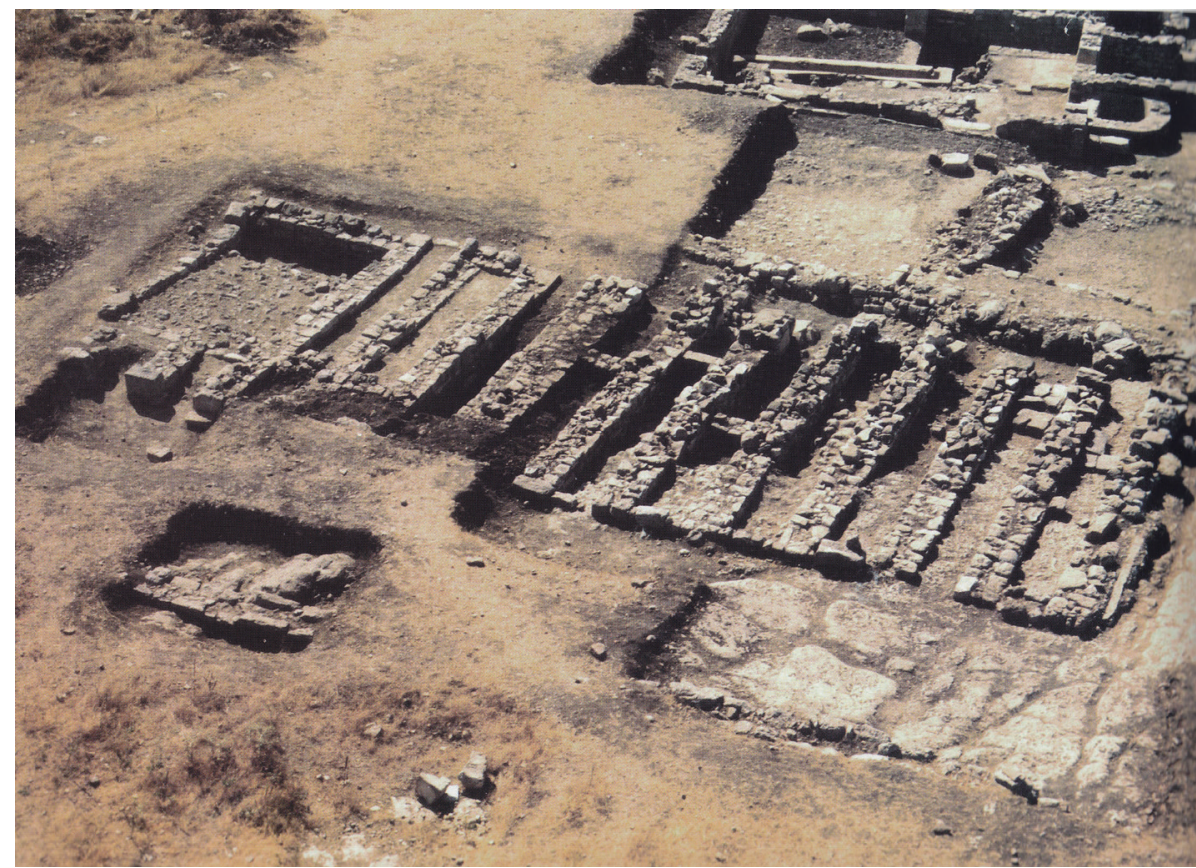

Figura 10. Vista general del horreum de la villa romana de Freiria (Cascais, Portugal). Imagen: Fabião 2006. 
gran eficacia y resistencia para soportar el enorme peso de la carga conservada en el interior.

Son diversos los problemas a la hora de identificar la presencia de varios tipos de apoyos. Es muy posible que los graneros sustentados sobre pilares o postes de madera contasen con mechinales y seguramente muchos agujeros de poste han pasado desapercibidos por los especialistas durante el proceso de excavación. Resulta también importante reconocer los cambios y reformas de la infraestructura, pues algunos horrea pudieron contar durante un primer momento con un solo tipo de soporte y, en un momento posterior, se dispusieron más para contrarrestar la inestabilidad de la cimentación.

En los establecimientos rurales la combinación de distintos tipos de soportes se constata exclusivamente en horrea del periodo bajoimperial. En la Península Ibérica, se testimonia el uso de pilares y banquetas en El Saucedo (Castilla-La Mancha, España) (Castelo, López Sáez, López Pérez, Peña, Liesau, Ruiz, López Merino, Pérez, García, Gómez, y Manglano 2010-2011). Sin embargo, en otras regiones el número de graneros correspondientes a este tipo es más numeroso.

\subsection{Los accesos y las rampas de carga/ descarga}

Los accesos en los horrea son espacios y estructuras de notable importancia, porque son elementos constructivos que no solo sirven de antesala del edificio, sino que juegan un papel central en la conservación del cereal almacenado. Generalmente, las cámaras de almacenaje estaban cerradas con puertas de madera, de las que no se han conservado testimonios materiales. En los graneros rurales hispanos, es habitual encontrar antesalas que permiten mantener un mayor aislamiento con respecto el exterior.
Es de suponer que estos espacios servirían también como lugares donde se podían guardar los aperos de labranza e incluso almacenar productos alimenticios en sacos. Estas antecámaras son simples estancias que se deben recorrer antes de entrar en el interior del granero, como podemos comprobar en los horrea de Freiria (Portugal), Veranes (Asturias), Cañaveral (Extremadura) o Torre de Palma (Portugal). En la antesala del granero de Veranes, hemos podido constatar los restos de un pavimento hidráulico de terrazo rojizo sobre un potente rudus de piedras calizas de mediano tamaño trabadas con argamasa (FernándezOchoa, Gil, Zarzalejos y Salido 2012: 131). Al oeste de la estancia, el pavimento se interrumpe para dar lugar a un espacio de $3 \mathrm{~m}$ de longitud por 2,80 $\mathrm{m}$ de anchura, donde debió levantarse en su día una pequeña rampa, que conducía a un descansillo por donde se accedía al almacén (Fig. 11). Esta estructura pudo ser de madera, ya que no han quedado evidencias de una posible fábrica de mortero y piedras. El acceso a esta antesala se hallaba en la esquina suroriental de la misma y la comunicación desde este espacio a la cámara de almacenaje se encontraba en el lado opuesto, lo que obligaba a cruzar la antesala para ir hasta el fondo de la misma. El acceso acodado evitaba el paso directo al ambiente habilitado como almacén y, con ello, el cambio brusco de temperatura y, sobre todo, de humedad en el interior de la sala de almacenaje. En el horreum de Monroy, hemos podido identificar, en cambio, dos accesos externos que comunican separadamente con las dos estancias del edificio: la antesala y la cámara de almacenaje. Hasta el momento no se había llamado la atención sobre el acondicionamiento del camino por donde se accedía a la entrada de la sala de almacenaje. Posiblemente se preparó para la llegada de los carros. La entrada estaba además flanqueada por dos muretes de piedra que servían de base de una rampa de madera (Fig. 12).

Figura 11. Propuesta de distribución de los ambientes en el horreum de Veranes (Asturias). Imagen: Fernández-Ochoa, Gil, Zarzalejos y Salido 2012: Figura 55.

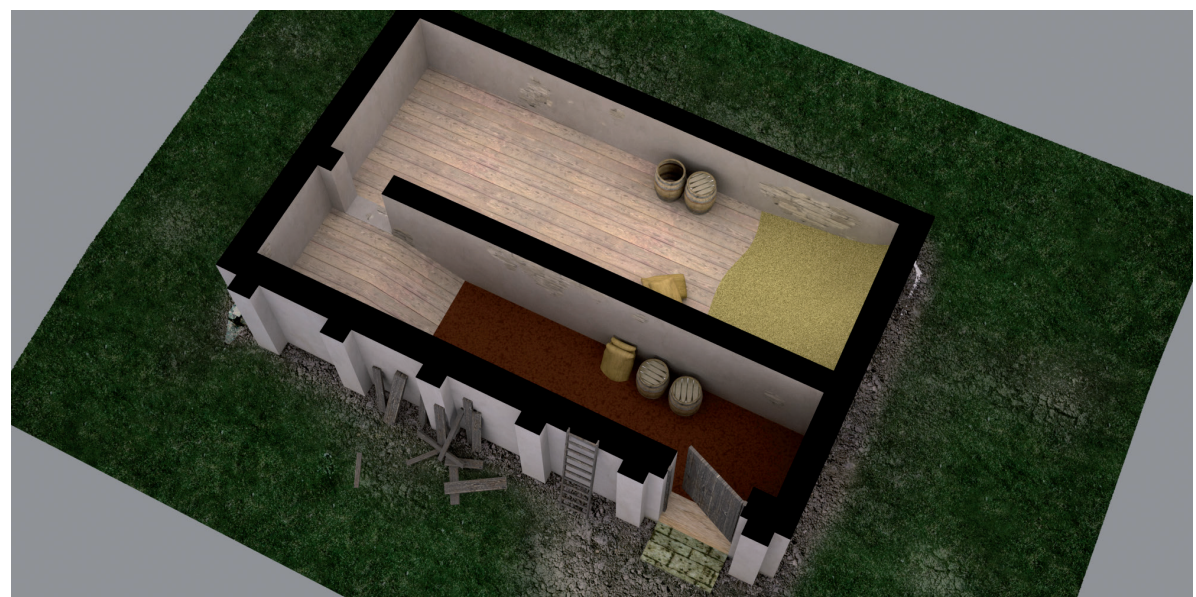



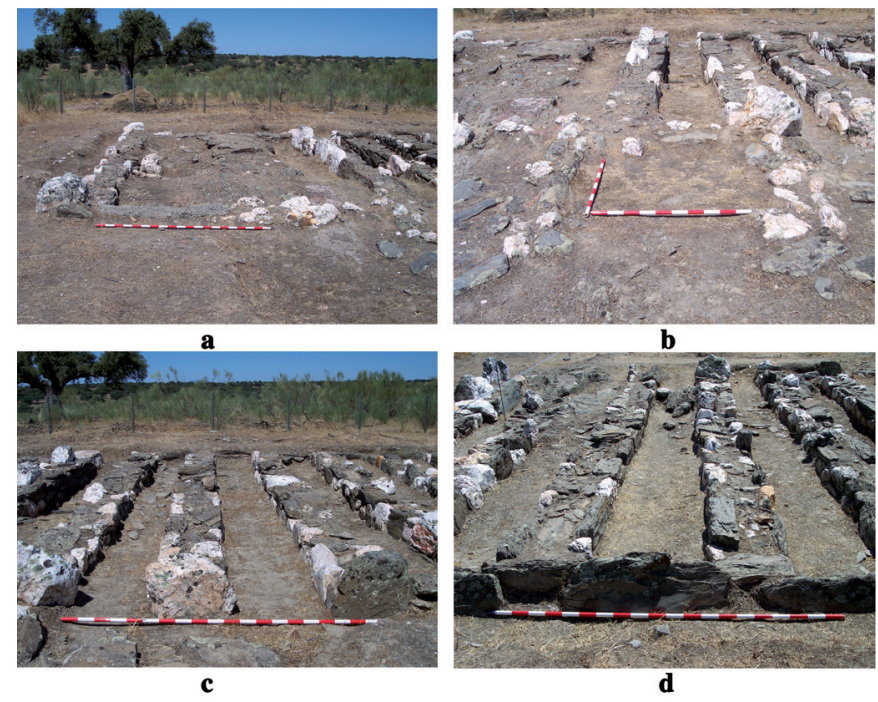

Figura 12. Detalles constructivos del horreum de la villa romana de Monroy (Extremadura): a- Acceso a la antesala con laja de marcación de la puerta; b- ingreso de la cámara de almacenaje, con suelo preparado para los carros y muros que sirven de base de una rampa; c- Muretes de soporte de la cámara vistos desde el sur; dCierre norte de los muros paralelos en que se aprecian las lajas que sirven para aislar este extremo del edificio. Fotografías: autor.

La ubicación de los accesos fue una elección importante también para la conservación del cereal almacenado; generalmente se situaban en las fachadas menores de los graneros. Estos edificios se solían construir con una orientación noreste-suroeste o noroestesureste, con el fin de evitar el aumento de la humedad en la cara norte o la insolación en la fachada sur (Salido 2003-2004: 470).

\subsection{Las techumbres}

La información que tenemos sobre la techumbre de los graneros es muy limitada y de forma habitual procede de evidencias indirectas (Salido 2011a: 111). Es probable que se instalaran tejados a dos aguas, con dos faldones que presentaban una inclinación suficiente como para desalojar el agua de lluvia. En el registro arqueológico, la evidencia más clara de la existencia de tejados es la aparición de tegulae e imbrices o pizarras utilizadas en la fabricación de la cubierta (Gentry 1976: 37-40); además la presencia de contrafuertes nos puede indicar el lugar donde se disponía el esqueleto de madera interno que permitía sostener el tejado. Hay que tener en cuenta que, además de techumbres construidas en material latericio o en pizarra, debió ser muy común la fabricación de cubiertas de madera. El enorme peso que debía soportar la infraestructura posiblemente motivó la generalización de tejados construidos en material lignario. Esto explicaría la ausencia o la escasa presencia de tegulae e imbrices en la mayoría de las excavaciones de horrea. Un testimonio indirecto que nos permite deducir el alero de las techumbres es la existencia de los canales de drenaje, como en el granero de Veranes, donde la anchura del conducto es de $20 \mathrm{~cm}$ (Fernández-Ochoa, Gil, Zarzalejos y Salido 2012: 136) (Fig. 6). Es frecuente que estas zanjas o canales de piedra nos indiquen el lugar donde finalizaba el alero del tejado en la parte superior, pues el agua de lluvia se desviaba hasta estos desagües.

\section{CONSIDERACIONES FINALES}

En este estudio nos hemos centrado en el análisis de los horrea hispanorromanos destinados al almacenaje de cereal y otros alimentos perecederos. Entre estas edificaciones, hemos analizado los datos más recientes de que disponemos sobre los graneros con pavimentos sobreelevados, con especial atención a los materiales y los sistemas empleados en su construcción.

El análisis de los materiales nos permite deducir que se emplearon mayoritariamente los de ámbito local, como nos indica el uso, entre otros, de cantos calizos en el granero de Veranes o la pizarra y el cuarzo blanco en Monroy, muy presentes en el entorno de los yacimientos. Más interesantes resultan los últimos estudios antracológicos realizados que, aunque todavía resultan escasos, nos permiten avanzar algunas hipótesis. La madera de pino resinero empleada en la construcción de la tarima del granero de El Saucedo, presente también en otros yacimientos de época romana, nos informa sobre la obtención local de los recursos leñosos, a diferencia de otras regiones donde la madera fue importada de otras regiones por vía marítima (Papi y Martorella 2007).

Desde el punto de vista constructivo, resultan especialmente interesantes estas estructuras, pues la necesidad de mantener unas condiciones ideales de temperatura y humedad en el interior obligó a la aplicación de determinadas normas arquitectónicas como la construcción de paramentos de gran anchura, en ocasiones dotados de contrafuertes. Estas paredes podían incluso contar con aberturas de ventilación que facilitaban el paso de aire por la parte inferior de la tarima del granero. Junto a éstos, se abrieron además zanjas de drenaje que evitaban la acumulación de agua en la parte más cercana al espacio reservado al almacenaje. Además de la cámara de almacenaje, contaban con antesalas que sirvieron 
no sólo como espacios que preservaban los cambios bruscos atmosféricos, sino también como lugares donde guardar otros pertrechos y ubicar las rampas de carga y descarga desde donde se vertía el cereal a granel al interior de la cámara de almacenaje. A partir del estudio de las estructuras hispanorromanas, podemos afirmar que en la mayoría de las ocasiones se emplean técnicas constructivas muy similares -instalación de pavimentos sobreelevados, contrafuertes, aberturas de ventilación, canales de drenaje - a las de los horrea de otras regiones del Imperio (Morris 1979; Demarez 1987; Sigaut 1988; Van Ossel 1992; Busana 2002; Heimberg 2002-2003) y otros sistemas diferentes como la colocación de lajas de pizarra para el sobrado del granero quedan pendientes de confirmación.

Respecto a la clasificación técnico-tipológica propuesta a partir de los apoyos de las cámaras de almacenaje, resulta difícil ofrecer una explicación definitiva. En nuestra opinión, no se atiene a una evolución cronológica - aunque el uso de pegollos se fechan a partir sobre todo de época flavia en ámbito militar y rural-, sino que se trata de una cuestión de practicidad. El hecho de que solamente se documente en el noroeste de la Península Ibérica el uso de pegollos para sobreelevar las cámaras de almacenaje, al modo de los hórreos actuales, podría explicarse por los altos niveles de humedad del entorno. Si nos fijamos en los dos factores ambientales importantes para la conservación del grano, es decir, la humedad a un nivel entre el 10 y el $15 \%$ y una temperatura en torno a $\operatorname{los} 15^{\circ} \mathrm{C}$. En esta región, no parece que ésta suponga un condicionante clave para su conservación, en cambio la humedad supera frecuentemente el nivel de $85 \%$. Los pegollos, a diferencia de los muros paralelos, permiten airear mejor la parte inferior del tabulatum, consiguiendo una mayor ventilación de la cámara de almacenaje ${ }^{6}$. Este factor podría explicar por qué este es el sistema más empleado en otras regiones como en la Venetia romana al norte de Italia, documentada en los asentamientos rurales de Isola Vicentina-loc. Fosse, Torre di Pordenone, Venezia Nuova, en la villa de Franzine Nuove, Pirin cerca de Aquileia y Russi (cf. Busana 2002: 193-194, fig. 89-90 y 95) y también en el norte de las provincias septentrionales en regiones como

\footnotetext{
${ }^{6}$ Este condicionante ambiental explicaría su uso también en otro tipo de asentamientos como en campamentos y en aglomeraciones secundarias militares del noroeste, donde también se han localizado horrea de este tipo. Es el caso del granero doble de Aquis Querquennis en Baños de Bande (Orense) (Salido 2011: 509-513) y del vicus militar de Puente Castro en León (Morillo, Salido y Durán 2015).
}

Nordrhein-Westfalen, en asentamientos rurales de Niederzier 111, 112, 127, 130, 132-4 y 206 de Hambach, Lürken, Köln-Müngersdorf 3 (cf. Heimberg 2002-2003: 121, fig. 46), en Hochneukirch (Keller 1997; Schuler 2000), WW 112 de Jülich-Kirchberg (Jenter y Wippern 1997; Päffgen 2000), en la región de Baden-Württemberg, en asentamientos rurales como Oberndorf-Bochingen (Sommer 2001), en Walldorf (Rabold 2002), en Kirchheim am Neckar (Luik y Müller 1995), en Bélgica, como en el establecimiento rural de Emptinne-Champion (Van Ossel y Defgnée 2001), en Ile-de-France, concretamente en Limetz-Villez (Van Ossel y Ouzoulias 1989) e Inglaterra, en Lullingstone (Kent) (Meates 1979). En cambio, por el momento el uso de muretes paralelos y de otros soportes se constata en regiones de la Península Ibérica de mayor sequedad. La amplia concentración de estos últimos en la Lusitania se puede atribuir más a un problema de índole arqueológico que por cuestiones prácticas, pues por el momento son escasos los horrea documentados en otros territorios como el centro y sur de la Península Ibérica. En definitiva, respecto a la difusión y distribución de los tipos en la Península Ibérica, poco más podemos adelantar por el momento y no cabe duda de que la continuación de los trabajos arqueológicos, cada vez más centrados en el estudio de las zonas productivas de las villae, nos permitirán en el futuro corroborar o refutar las hipótesis aquí expuestas.

\section{BIBLIOGRAFÍA}

Aguilar Saenz, A. y Guichard, P. 1993: Villas romaines d'Estrémadure. Doña María, La Sevillana et leur environnement, Madrid.

Alarcão, J., Etienne, R. y Mayet, F. 1990: Les villas romaines de São Cucufate. Fouilles de Conimbriga, Paris.

Bacchetta, A. 2003: Edilizia rurale romana: materiali e tecniche costruttive nella Pianura Padana (II sec. a.C.-IV sec.), Firenze.

Blaising, J. M. y Vanmoerkerke, J. 2005: Les bâtiments à supports inclinés dans l'architecture de la fin de l'Age du Fer et du début de l'époque gallo-romaine en Champagne et en Lorraine. Bulletin de la Société Archéologique Champenoise 2, Reims.

Busana, M. S. 2002: Architetture rurali nella Venetia romana, Roma.

Caballero Zoreda, L. 1996: "El análisis estratigráfico de construcciones históricas", L. Caballero y C. Escribano (eds.), Arqueología de la Arquitectura. El método arqueológico aplicado al proceso de estudio y de intervención en edificios históricos, Burgos, 55-74.

Caballero Zoreda, L. y Escribano Velasco, C. 1996 (eds.): Arqueología de la Arquitectura. El método arqueológico aplicado al proceso de estudio y de intervención en edificios históricos, Burgos.

Caballero Zoreda, L. y Utrero Agudo, M. A. 2005: "Una aproximación a las técnicas constructivas de la Alta Edad Media en la Península Ibérica. Entre visigodos y omeyas", Arqueología de la Arquitectura 4, 169-192.

Camporeale, S. 2004: "Tecniche edilizie in pietra nella Mauretania Tingitana tra l'epoca mauretana e romana. Osservazioni sulle apparecchiature e utilizzo della malta", Archeologia dell'Architettura IV, 195-205. 
Castelo, R., López Sáez, J. A., López Pérez, A. M. a, Peña, L., Liesau, C., Ruiz, M., López, L., Pérez Merino, S., García, R., Gómez, J. L. y Manglano, G. 2010-2011: "Una aproximación interdisciplinar a las actividades agropecuarias y cinegéticas de un asentamiento rural lusitanoEl Saucedo (Talavera la Nueva, Toledo)", Boletín de la Asociación Española de Amigos de la Arqueología, 46, 205-234.

Cerrillo Martín de Cáceres, E. 2006: "La villa romana de Monroy. Reflexiones sobre la complejidad rural en época romana", A. Chavarría Arnau, J. Arce y G. P. Brogiolo (eds.), Villas Tardoantiguas en el Mediterráneo Occidental, Anejos AEspA 39, Madrid, 197-206.

Demarez, J. D. 1987: "Les bâtiments à fonction économique dans le fundi de la Provincia Belgica", Amphora 50, 1-36.

Domergue, C. y Hérail, G. 1978: Mines d'or romaines d'Espagne: le distritc de la Valduerna (León). Étude géomorphologique et archéologique, Toulouse.

Drake, B. 2006: "Excavación arqueológica en el yacimiento de los sectores plataforma norte y sur del yacimiento 12 B (Carrascalejo)", Extremadura arqueológica, 10, 213-232.

Eiden, H. y Mylius, H., 1949: "Untersuchungen an den spätrömischen Horrea von St. Irminen in Trier», Trierer Zeitschrift 18, 73-98.

Encarnaçao, J. D’. y Cardoso, G. 1992-1993: “A villa romana de Freiria e o seu enquadramento rural", Studia Historica. Historia Antigua, 10-11, 203-217.

Fabião, C. 2006: A Herança Romana em Portugal, Lisboa.

Fernández Mier, M. y Quirós Castillo, J. A., 2001: La evolución de las técnicas constructivas en Asturias en la Edad Media, V Congreso de Arqueología Medieval Española 1, 371-382.

Fernández-Ochoa, Gil, Zarzalejos y Salido 2012: El horreum de la villa romana de Veranes (Gijón, Asturias). Primer testimonio material de los hórreos de Asturias, Madrid.

Gentry, A. P. 1976: Roman military stone-built granaries in Britain, BAR British Series 32, Oxford.

Gracia Alonso, F. 1995: "Producción y comercio de cereal en el N.E. de la Península Ibérica entre los siglos VI-II a.C.", Pyrenae 26, 91-113.

Gracia Alonso, F. 2009: "Producción y almacenamiento de excedentes agrícolas en el NE. peninsular entre los siglos VI y II a. C. Análisis crítico", R. García Huerta y D. Rodríguez González (eds.): Sistemas de almacenamiento y conservación de alimentos entre los pueblos prerromanos peninsulares, Humanidades 103, Cuenca, 9-72.

Gracia Alonso, F. y Munilla, G. 2000: "Los graneros sobreelevados en el Mediterráneo Occidental II”, R. Buxó y E. Pons (eds.), Els productes alimentaris d'origen vegetal a l'edat del ferro de l'Europa occidental: de la producció al consum, Actes del XXII col•loqui internacional per a $1^{\prime}$ estudi de 1 'edat del ferro. Association française pour l'étude de l'Âge du Fer. Sèrie Monogràfica Museu d'arqueologia de Catalunya 18, Girona, 339-349.

Heimberg, U. 2002-2003: "Römische Villen an Rhein und Maas", BJ 202203, 57-148.

Jenter, S. y Wippern, J. M. 1997: "Prospektionsergebnisse von einer römischen Villa rustica bei Kirchberg", Archäologie im Rheinland 1996, 177-180.

Jiménez, M., González, I., Requejo, O. y Ruiz, M. B. (2004): “Geoarqueología en los yacimientos romanos de Paredes (Asturias): aspectos geomorfológicos", G. Benito y A. Herrero (eds.): Contribuciones recientes sobre Geomorfología, Madrid, 193-201.

Keller, C. 1997: "Eine villa rustica in Hochneukirch", Archäologie im Rheinland 1997, 55-57.

King, A. C. 1996: "The south-east façade of Meonstoke aisled building", P. Johnson y I. Haynes (eds.), Architecture in Roman Britain, CBA Research Report 94, York, 56-69.

López Sáez, J. A. 2012: “Análisis paleobotánicos”, C. Fernández-Ochoa, F. Gil, M. Zarzalejos y J. Salido 2012, El horreum de la villa romana de Veranes (Gijón, Asturias). Primer testimonio material de los hórreos de Asturias, Madrid, 161-170.

Lozano Apolo, G. y Lozano Martínez-Luengas, A. 2003: Hórreos, cabazos y garayas, Oviedo.
Luik, M. y Müller, D. 1995: Römerzeitliche Geländedenkmäler. 1. Die römischen Gutshöfe von Gemmrigheim und Kirchheim am Neckar (Landkreis Ludwigsburg), Atlas archäologischer Geländedenkmäler in BadenWürttemberg 3 (1), Stuttgart.

Macías Solé, J. M. 2011: "Horrea y estructuras de almacenamiento en la ciudad y territorio de Tarraco: una primera aproximación”, J. Arce y B. Goffaux (eds.): Horrea d'Hispanie et de la Méditerranée romaine, Madrid, 185-200.

Maloney, S. y Hale, J. 1996: "The villa of Torre de Palma (Alto Alentejo)", JRA 9, 275-294.

Manning, W. H. 1975: "Roman military timber granaries in Britain", SJ 32, 105-129.

Matterne, V. 2001: Agriculture et alimentation végétale durant l'âge du Fer et l'époque gallo-romaine en France septentrionale, Montagnac.

Matterne, V., Yvinec, J. H., Gemehl, D. y Riquier, Ch. (1998): “Stockage de plantes alimentaires et infestation par les insectes ans un grenier incendié de la fin du IIe siècle après J.-C. à Amiens (Somme)", RAPic 1998 (3-4), 93-122.

Meates, G. W. 1979: The Roman villa at Lullingstone, Kent, 1. The site. Monograph series of the Kent Archaeological Society 1, London.

Monteix, N. 2008: "La conservation des denrées dans 1' espace domestique à Pompéi et Herculanum", MEFRA 120 (1), 123-138.

Morillo, A., Salido, J. y Durán, R. 2015: “Aglomeraciones secundarias de carácter militar en Hispania”, Anejos CUPAUAM 1, 117-132.

Morris, P., 1979: Agricultural Buildings in Roman Britain, BAR international series 70, Oxford.

Moutoso Batata, C. A. 2006: Idade do ferro e romanização entre os rios Zêzere, Tejo e Ocreza, Lisbonne.

Olmedo Grajera, A. B. y Vargas Calderón, J. 2004: "Una qarya emiral de la kūra de Mārida: intervención arqueológica en la finca «Royanejos»", Mérida: Excavaciones Arqueológicas. Memoria, 10, 15-46.

Päffgen, B., 2000: "Villa rustica und Burgus auf dem Steinacker in JülichKirchberg", H. G. Horn (dir.), Fundort Nordrhein-Westfalen. Millionen Jahre Geschichte, Schriften zur Bodendenkmalpflege in Nordrhein-Westfalen 5, Mainz, 283- 284.

Pais, A. 2008: "L'edilizia romana nella toscana tirrenica alla luce dell'archeologia dell'architettura", S. Camporeale, H. Dessales y A. Pizzo (eds.): Arqueología de la Construcción I. Los procesos constructivos en el mundo romano: Italia provincias y occidentales, Anejos de Archivo Español de Arqueología 50, Madrid, 67- 88.

Papi, E. y Martorella, F. 2007: "Il grano della Tingitana", E. Papi (ed.): Supplying Rome and the Empire, JRA. Supplementary Series 69, Portsmouth, 85-96.

Picado Pérez, Y. 2001: "Nuevos datos para el conocimiento del área periurbana de Mérida en época altoimperial: la villa de Carrión. Intervención arqueológica realizada en el trazado de la Autovía de la Plata (tramo Mérida-Almendralejo Sur)", Mérida. Excavaciones arqueológicas, 7, 231-246.

Pizzo, A. 2010a: "Propuesta para la documentación y clasificación de las técnicas constructivas romanas", Arqueología de la Arquitectura 7, 277 286.

Pizzo, A. 2010b: Las técnicas constructivas de la arquitectura pública de Augusta Emerita, Anejos de AEspA 56, Madrid.

Poux, M., Borlenghi, A., Courtot, A., Leperlier, M., Blanc, F. y Lassus, J. 2012: Panossas "Les Buissières», Commune de Panossas (Isère) Arrêté

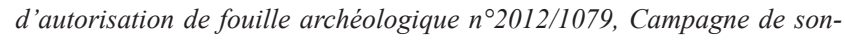
dages 2012.

Rabold, B. 2002: "Roömisches Landgut oder kaiserliche Domäne bei Walldorf, Rhein-Neckar-Kreis", Arch. Ausgr. Baden-Württemberg 2001, 138-142.

Révillion, S., Bouche, K. y Wozny, L. 1994: "La partie agricole d'une grande exploitation rurale d'époque romaine: le gisement du Haut de Clauwiers, Seclin, Nord", Revue du Nord, 76 (308), 99-146.

Rickman, G. 1971: Roman granaries and store buildings, Cambridge.

Royet, R., Berger, J. F., Bernigaud, N. y Royet, E. 2004: "La gestion d'un milieu humide: le site du Vernai et le marais du Grand-Plan à Saint-Romain-de-Jalionas (Isère), de La Tène au Haut Moyen-Age", J. Burnouf 
y $\mathrm{Ph}$. Leveau (dirs.): Fleuves et marais, une histoire au croisement de la nature et de la culture, CTHS, 253-281.

Salido Domínguez, J. 2003-2004: "La documentación literaria aplicada al registro arqueológico: las técnicas de construcción de los graneros romanos rurales", Espacio, Tiempo y Forma. Serie I: Prehistoria y Arqueología, 16-17, 463-478.

Salido Domínguez, J. 2008: "Los sistemas de almacenamiento y conservación de grano en las villae hispanorromanas", C. Fernández-Ochoa, V. García-Entero y F. Gil Sendino (eds.), Las villae tardorromanas en el Occidente del Imperio. Arquitectura y función, Gijón, 693-706.

Salido Domínguez, J. 2009: "Los graneros militares romanos de Hispania", A. Morillo, N. Hanel y E. Martín (eds.), Limes XX. Estudios sobre la Frontera Romana, Anejos de Gladius 13, volumen 2, Madrid, 679-692.

Salido Domínguez, J. 2011a: Horrea Militaria. El aprovisionamiento de grano al ejército en el Occidente del Imperio Romano, Anejos de Gladius 14, Madrid.

Salido Domínguez, J. 2011b: "El almacenamiento de cereal en los establecimientos rurales hispanorromanos", J. Arce y B. Goffaux (éds.), Horrea d'Hispanie et de la Méditerranée romaine, Madrid, 127-142.

Salido Domínguez, J. 2013: "El abastecimiento de grano a las ciudades hispanorromanas. Producción, almacenaje y gestión”, Archivo Español de Arqueología, 86, 131-148.

Santos, F. J. C. 2009: A villa romana da Quinta da Fórnea I-Belmonte. Relatório de Progresso, Belmonte.
Schucany, C. 2006: Die römische Villa von Biberist-Spitalhof/SO. (Grabungen 1982, 1983, 1986-1989). Untersuchungen im Wirtschaftsteil und Überlegungen zum Umland. Ausgrabungen und Forschungen 4. Zürich.

Schuler, A. 2000: "Abschlussgrabung in Hochneukirch: von der Protovilla zur villa rustica”, Archäologie im Rheinland 2000, 69-72.

Sigaut, F. 1988: "A method for identifying grain storage techniques and its application for European Agricultural History", Tools \& Tillage 6, 3-32.

Sommer, C. S. 2001: "Ein Grosses landwirtschafliches Nebengebäude in Oberndorf-Bochingen, Kreis Rottweil. Aspekte der römischen Architektur", Arch. Ausgr. Baden-Württemberg 2000, 117-121.

Van Ossel, P. 1992: Établissements ruraux de l'Antiquité tardive dans le Nord de la Gaule, Paris.

Van Ossel, P. y Defgnée, A. 2001: Champion, Hamois: une villa romaine chez les Condruses: archéologie, environnement et économie d'une exploitation agricole antique de la Moyenne Belgique, Etudes et documents. Archéologie 7, Namur.

Van Ossel, P. y Ouzoulias, P. 1989: "Römische Villa und Frühmittelalterliche Siedlung in Limetz-Villez (Dép. Yvelines, Frankreich)”, AKB 19, 391-396.

Vargas Calderón, J. y Matesanz Vera, P. 2006: "Excavación arqueológica yacimiento número 6-8: Plasencia sur - Cañaveral este", Extremadura arqueológica, 10, 115-144.

Virlouvet, C. 2009: "Entrepóts de stockage, entrepóts et marchés. Pour une typologie des horrea dans 1'Afrique du Nord Antique", Antiquités Africaines 43. L'Afrique du Nord de la protohistoire à la conquête arabe, 165-170. 